
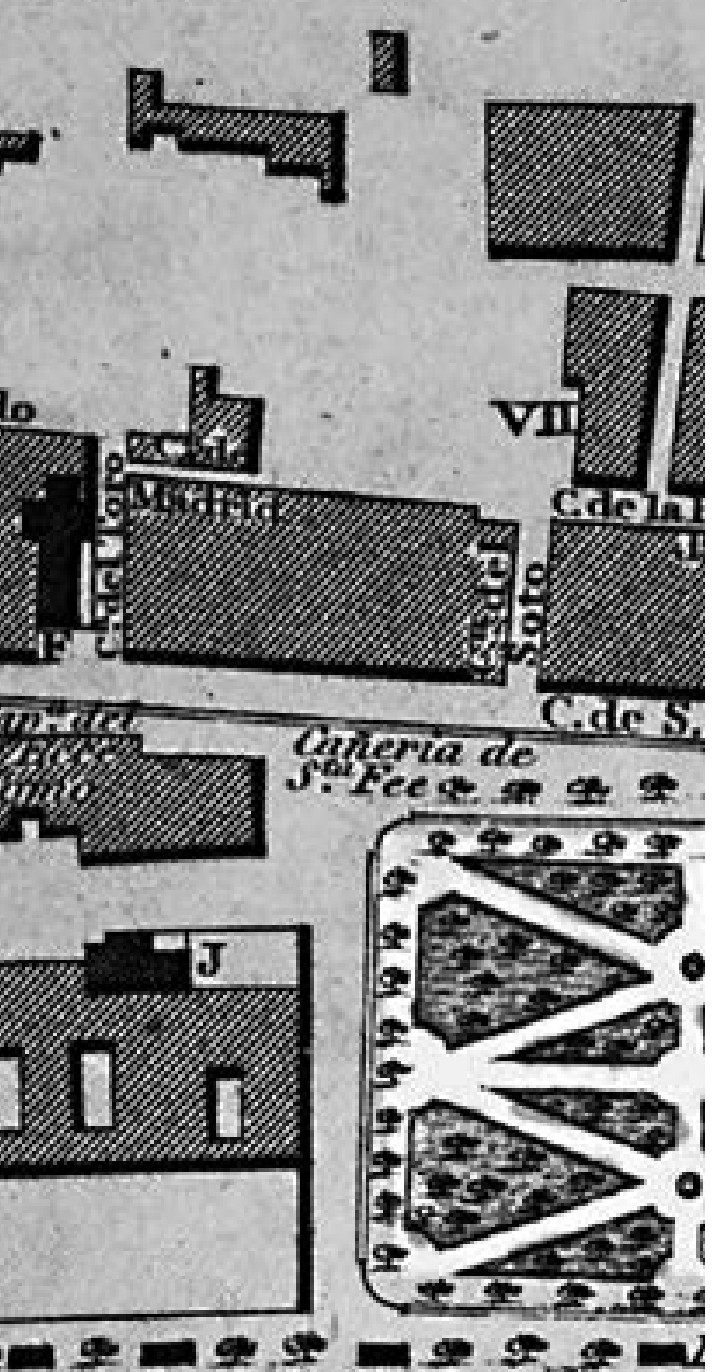
C.del Calvario

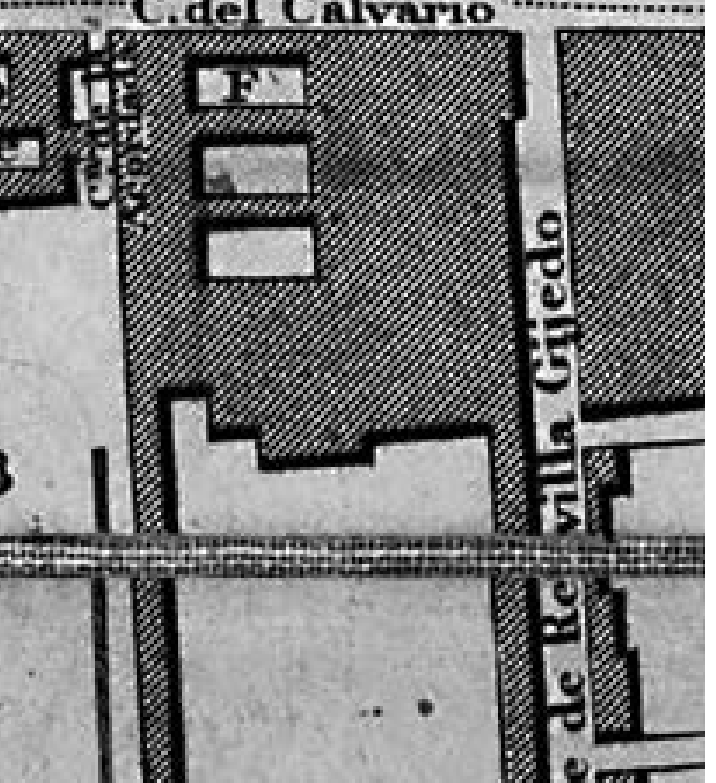

\section{Arqueología y arquitectura en la conservación del patrimonio. El caso de República de Cuba \\ núm. 32, en la Ciudad de México}

Archeology and Architecture in Heritage Conservation. The Case of 32 República de Cuba Street, Mexico City

Patricia Viridiana Sánchez Ramírez

Universidad Nacional Autónoma de México (UNAM), México

yax_kinn@hotmail.com

\section{Resumen}

En la segunda mitad del siglo XIX, como producto de la aplicación de las Leyes de Reforma, la arquitectura en la Ciudad de México entró en un proceso de cambio: las viviendas construidas en esa época incorporaron a su diseño las necesidades sociales, e integraron modelos de habitación heredados del virreinato mediante programas y materiales derivados de la Revolución industrial. Las viviendas plurifamiliares de la calle República de Cuba núm. 32, en el Centro Histórico de la Ciudad de México, son un claro ejemplo de esas modificaciones y de cómo, a lo largo de los años, el espacio habitado se transformó de acuerdo con las dinámicas sociales de sus habitantes. Transformaciones que es posible conocer gracias a la aplicación de la arqueología de la arquitectura y de las que da cuenta este ENSAYO.

\section{Palabras Clave}

arqueología de la arquitectura; vivienda plurifamiliar; Centro Histórico; Ciudad de México; siglo XIX; arquitectura doméstica

\section{Abstract}

During late $19^{\text {th }}$ century, architecture in Mexico City went through a process of change as a result of the implementation of the Reform Laws: the dwellings built at that time incorporated social needs into their design, and integrated housing models inherited from the Viceroyalty of New Spain through programs and materials derived from the industrial revolution. The multi-family dwellings in 32 República de Cuba street, in the Historic Center of Mexico City, are a clear example of these modifications and of how, throughout the years, the inhabited space was transformed in accordance with the social dynamics of its inhabitants. It was posible to follow these transformations through the application of the archeology of architecture, and this ESSAY gives account of it. 
Keywords

archeology of architecture; multi-family dwelling; historic center;

Mexico City; $19^{\text {th }}$ century; household architecture

\section{Introducción}

No se puede conservar lo que no se quiere, y no se puede querer lo que no se entiende.

FREEMAN TILDEN

E n el ámbito de la conservación del patrimonio, cada día se trabaja más de manera multidisciplinaria. Diferentes áreas del conocimiento estudian las diversas aristas de proyectos de conservación. Sin embargo, dentro de las investigaciones, el objetivo principal: la preservación de los monumentos, raras veces deja espacio para investigaciones sobre los inmuebles en sí mismos y acerca de la historia que puede contar su contexto histórico, social, económico o incluso tecnológico. Esto es, un análisis de la arquitectura más allá de su historia documentada, enfocada como producto de su cultura desde una perspectiva arqueológica, implicaría conocer las modificaciones en sus espacios y, por ende, los procesos sociales que les dieron origen. Conocer las huellas culturales dejadas en los inmuebles por el paso del tiempo nos acercan a la historia no sólo del edificio sino de la sociedad que lo creó, a nuestra cultura.

Por ello, la intención del presente ENSAYO es plantear un estudio interdisciplinario como parte fundamental para cualquier proyecto de monumentos arquitectónicos. En esa misma línea, se expone la investigación hecha en el inmueble plurifamiliar ubicado en República de Cuba núm. 32, en el Centro Histórico de la Ciudad de México, donde el análisis arqueológico de su arquitectura doméstica evidencia la pertinencia y urgencia de estudiar interdisciplinariamente los proyectos de conservación.

\section{Arqueología de la arquitectura}

Desde hace varios años se ha defendido la perspectiva interdisciplinaria como el camino más completo de la investigación. No escapa a ello el tema de la conservación del patrimonio, donde el trabajo de restauradores, arqueólogos, arquitectos, historiadores y otros especialistas converge en su protección y la de su memoria histórica, sin embargo, las aproximaciones al tema generalmente se llevan a cabo desde su disciplina y pocas veces desde un trabajo conjunto, de la mano de otros profesionales. En ese sentido, considero que la aportación de la arqueología de la arquitectura es de gran valía para la preservación de los inmuebles históricos.

¿Arqueología de la arquitectura? El término fue acuñado en Italia por el arqueólogo Tiziano Mannoni en la década de 1990 (Mannoni 1990). Lo propuso con la finalidad de agrupar toda una serie de investigaciones que, provenientes de la arqueología, se aplicaban a los estudios arquitectónicos del patrimonio. Es decir, le dio nombre a toda una metodología de trabajo que si bien se utilizaba recurrentemente, aún no se designaba como disciplina específica.

Actualmente, la arqueología de la arquitectura se considera un método de investigación sobre la historia arquitectónica del edificio, y una herramienta básica para proyectos de conservación y restauración. Implica estudios tipológicos sobre los materiales, procesos y sistemas constructivos del pasado por medio de la estratigrafía de paramentos y de la aplicación de estudios arqueométricos (Serrano 2013). Al mismo tiempo, una perspectiva antropológica como lo es la arqueología promueve el desarrollo de investigaciones interpretativas, en contraste con los estudios centrados únicamente en estilos y corrientes arquitectónicos.

La arqueología de la arquitectura no pretende ser una nueva rama de nada, una nueva moda de las que proliferan en los últimos años, ni siquiera un nuevo término para añadir a una lista inútil. Se trata de una manera de gestionar, estudiar y conservar una parte de la Cultura Material de las sociedades pasadas [Quirós 1994: 142].

Por medio de este tipo de análisis no sólo se identifican materiales y procesos constructivos asociándolos a un contexto determinado, sino también se facilita y se da sustento a una adecuada propuesta de preservación de los inmuebles que prevea las características de los materiales y los sistemas originales: más aún, principalmente, abre la puerta a una investigación más antropológica y social, al determinar las transformaciones arquitectónicas de los espacios al paso del tiempo y, con base en ello, inferir sus modificaciones y el uso social que le fue asignado a cada uno a lo largo de los años.

La manera de habitar un inmueble se transforma a la par de las temporalidades históricas. El contexto políticoeconómico-social se vincula directamente con las necesidades de la sociedad y, a su vez, en la búsqueda de satisfacerlas, modifica su espacio habitable para adecuarlo a éstas. "Los edificios afectan las relaciones que se dan entre las personas que los usan pero al mismo tiempo, como construcciones, expresan ideas" (Cohen 2011: 11). Estas huellas dejadas al correr de los años por los diferentes modos de vida son observables en las transformaciones de los espacios arquitectónicos, ya sea por el cambio de dimensiones, de materiales o de sistemas constructivos.

El estudio de la arquitectura por la arqueología es posible, al ser la arquitectura un producto humano. "El edificio arquitectónico, como documento histórico, es de por sí un yacimiento arqueológico" (Quirós 1994: 142). Como decía Villagrán (1989: 236), "todo programa [arquitectónico] posee dos determinantes ubicatorios, uno en la espacialidad geográfica y otro en la temporalidad 
histórica"; como tal, es susceptible de estudiarse como cultura material que habla de una sociedad en particular, es decir, de estudiarse como objeto arqueológico, aunque su estado no sea de ruina.

La arquitectura aparece como contexto arqueológico en tanto permite determinar funciones sociales del espacio, éstas resultan de la asociación entablada con los artefactos o el utillaje, en un primer nivel; como sistema, la arquitectura está integrada por elementos o componentes que interactúan para contener al espacio. En su papel de elemento componente, ésta (en forma de edificios, plazas y circulaciones) forma parte del asentamiento: lo configura, articula y organiza. Así, el espacio arquitectónico no es un artefacto, lo son los elementos que le contienen. Sin embargo éste se produce, se utiliza, se consume y, como los artefactos, permanece tangiblemente [Villalobos 1992: 65].

\section{República de Cuba núm. 32}

En el Centro Histórico de la Ciudad de México, en lo que fue el antiguo barrio de Santa María Cuepopan, en el siglo XVI se construyó el convento de Nuestra Señora de la Inmaculada Concepción, el más suntuoso y rico convento femenino de la Ciudad de México del virreinato (Figura 1). Sin embargo, con la creación y ejecución de las Leyes de Reforma, el convento fue seccionado y vendido en aras tanto del progreso y la modernización urbanos como de cortar para siempre con la herencia colonial y religiosa. Tras su destrucción, la renovación incluyó la apertura de nuevas calles, como la expansión de la actual Héroes del 57 y del callejón de Dolores (Figura 2), al igual que la construcción de inmuebles destinados a la habitación en donde fueron propiedades de la iglesia en la antigüedad.

La construcción del inmueble de República de Cuba núm. 32 se enmarca en la segunda mitad del siglo XIX, caracterizada por presentar un incremento poblacional, consecuencia de las diferentes migraciones hacia la capital del país. Esa situación generó, desde luego, mayores necesidades habitacionales, que encontraron respuesta en la construcción de viviendas plurifamiliares en el centro de la ciudad.

En ese sentido, los cambios en el modo de vida de la época también tuvieron repercusión en la arquitectura doméstica, no solamente al plantear nuevas necesidades de habitación, sino también porque los edificios sufrieron transformaciones en sus espacios interiores, producto de los cambios culturales y sociales, que a lo largo del tiempo modificaron la idea de habitar. En uno de los terrenos expropiados al antiguo convento de La Concepción, sobre la antigua calle de Dolores, ahora República de Cuba, se edificó el objeto de estudio (Figura 3), con diseño y materiales que dan cuenta de la historia de las transformaciones en el uso social de un espacio.

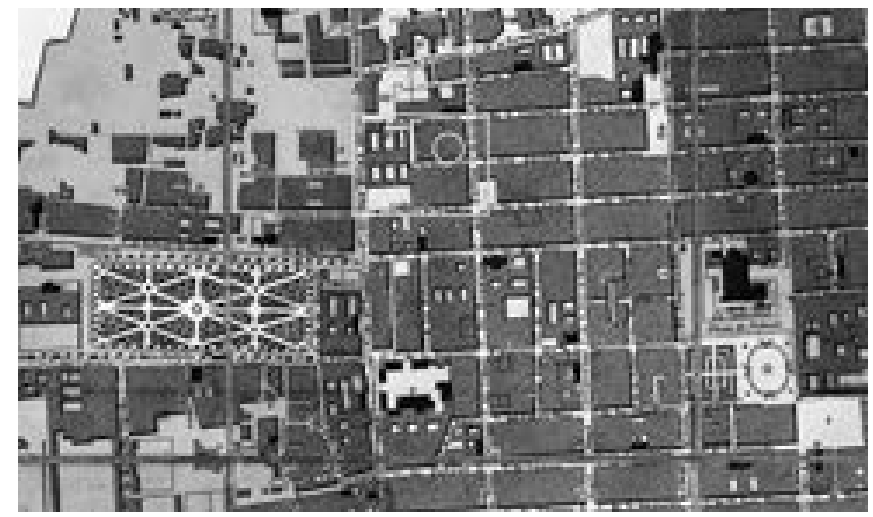

FIGURA 1. Sección del Plano general de la Ciudad de México levantado por el teniente coronel don Diego García Conde en el año de 1793, grabado en miniatura en Londres por Eduardo Mogg en el año de 1811. Se enmarca el área del convento de la Concepción y se engloba el lugar donde se edificaría el objeto de estudio (Fuente: Herrera y de Ita 1992: 164).

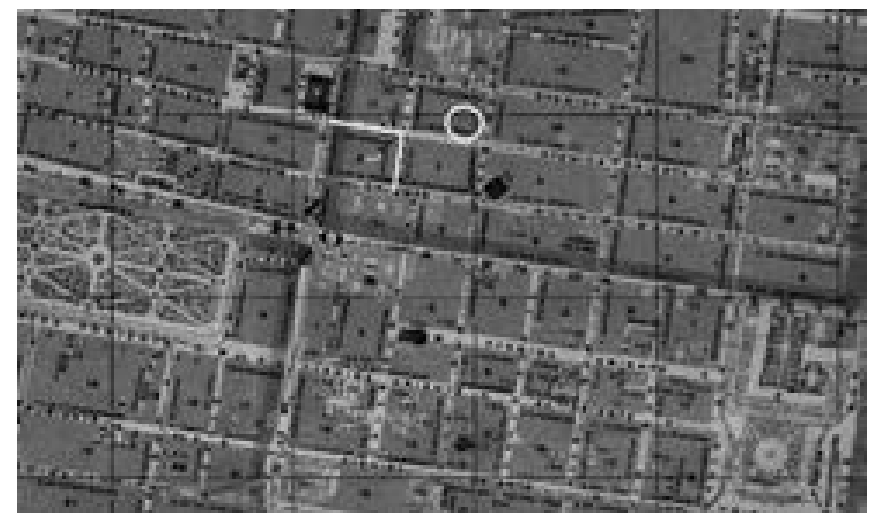

FIGURA 2. Sección del Plano oficial de la Ciudad de México por la Dirección de Obras Públicas y la Oficina Técnica de Saneamiento, detallado y publicado por la Compañía Litográfica y Tipográfica en el año de 1900. Se señala el área de construcción del objeto de estudio (Fuente: Pérez 2012: 51).

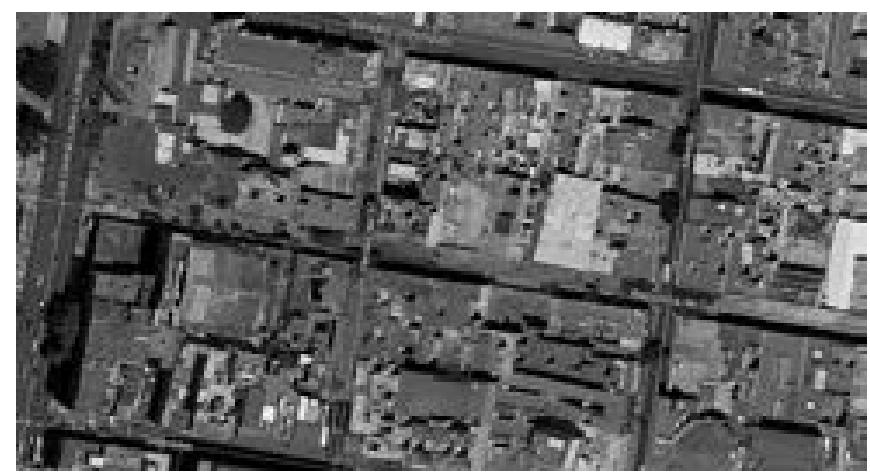

FIGURA 3. Ubicación actual de República de Cuba núm. 32 (Mapa: Google Earth®, 2018).

En un inicio, las viviendas de República de Cuba núm. 32 se planearon como parte de una solución al mencionado incremento en la demanda de habitaciones. En el estudio de Morales y Gayón (2001) se evidencia el crecimiento de viviendas en la época del inmueble: en 1882 se reporta para la manzana del inmueble entre 62 y $100 \%$ 
de viviendas, en relación con 1848, cuando solamente se tenía registrado entre 15 y $17 \%$.

El diseño del inmueble es interesante, ya que, por un lado, su programa arquitectónico semeja el modelo de vecindad heredado del virreinato (Katzman 1993), el cual consiste en numerosas viviendas de diversos tamaños distribuidas en torno de un patio (Martín 1981: 104), y en una fachada sencilla con accesorias o espacios para el comercio ubicadas en la planta baja (Figura 4). Ese patio (Figura 5) es el elemento más característico de las vecindades, al ser el área de servicios comunes, como los sanitarios y los lavaderos, donde se fomenta la convivencia

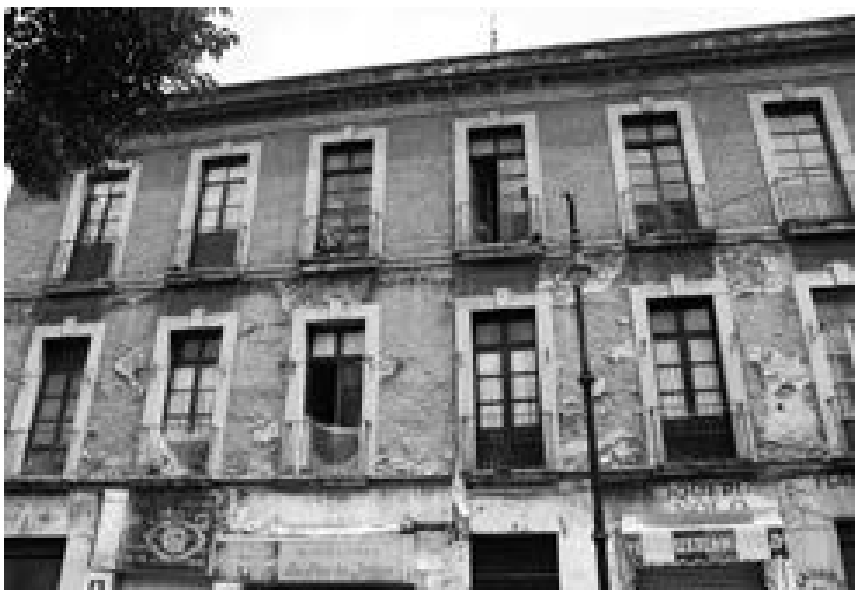

FIGURA 4. Fachada principal de República de Cuba núm. 32 (Fotografía: Patricia Sánchez, 2017).

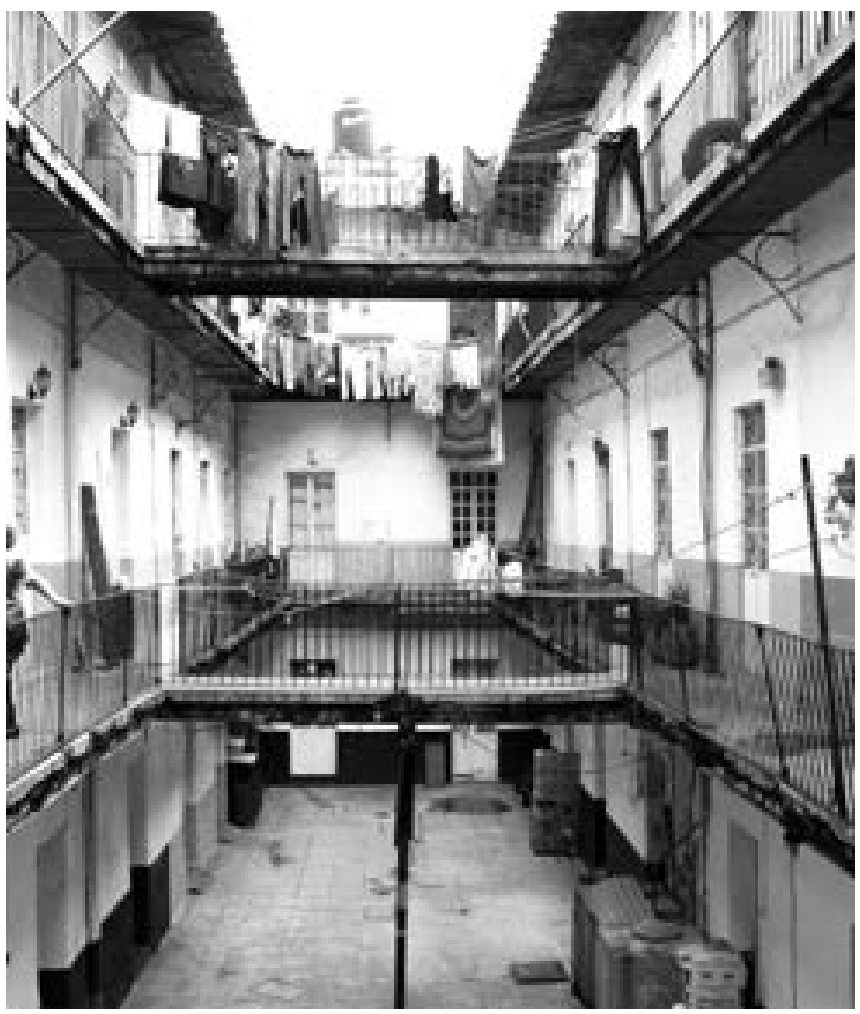

FIGURA 5. Patio central de República de Cuba núm. 32 (Fotografía: Patricia Sánchez, 2017). entre los vecinos de diferentes estratos sociales que habitan las viviendas (Muriel 1992).

Por otro lado, en algunos detalles del inmueble se observa la entrada a la modernidad: el uso de materiales como el acero y de novedosos sistemas de andadores que permiten conectar las viviendas con las escaleras (Figura 6), en conjunto con modernas marquesinas de metal en el último nivel, para dar sombra y protección de las Iluvias en los corredores (Figura 7).

Al mismo tiempo, la distribución de los espacios al interior de República de Cuba núm. 32 muestra la importancia que cobró la vida privada: al eliminar de su programa los lavaderos y los sanitarios del patio, se hizo a un lado la convivencia entre vecinos (Ayala 2009). Esas viviendas se diseñaron con un cuarto de baño y un área de azotehuela para lavadero propio. Asimismo, se contaba ya con amplias y diferentes habitaciones dentro de cada departamento para separar actividades: el espacio para cocinar dejó de ser el mismo donde se comía o descansaba, característica que indica el cambio en la idea de habitar del estrato poblacional para el que se construyó el inmueble.

Por lo tanto, la vivienda plurifamiliar de República de Cuba núm. 32, si bien data del siglo XIX, se trata de la

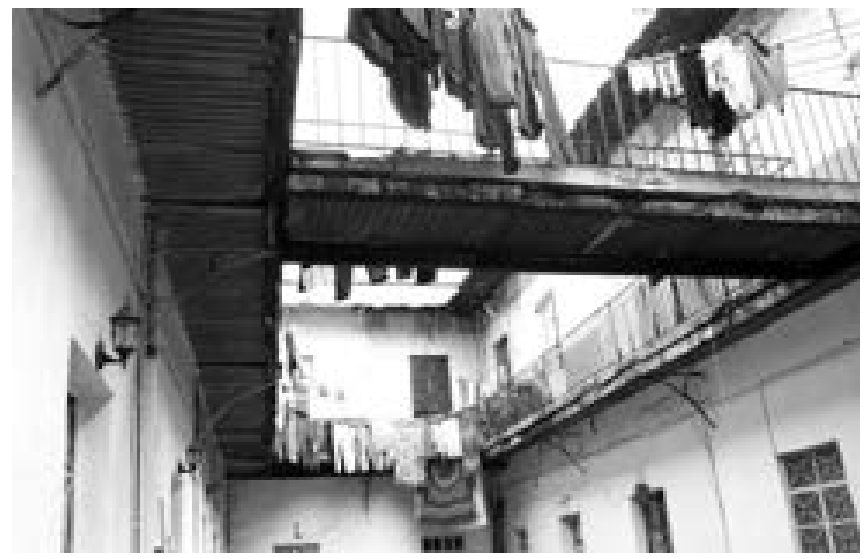

FIGURA 6. Sistema de andadores de vigueta y lámina de metal al interior de República de Cuba núm. 32 (Fotografía: Patricia Sánchez, 2017).

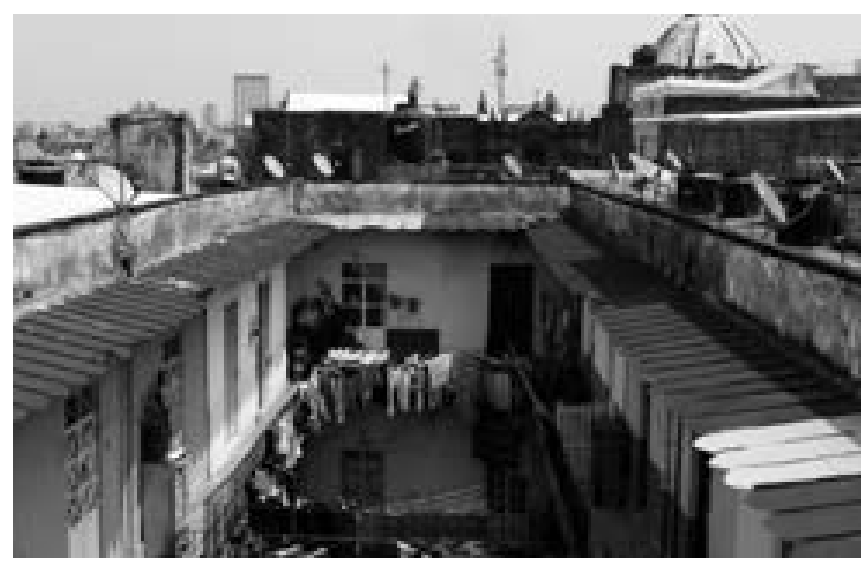

FIGURA 7. Marquesinas de metal al interior de República de Cuba núm. 32 (Fotografía: Patricia Sánchez, 2017). 

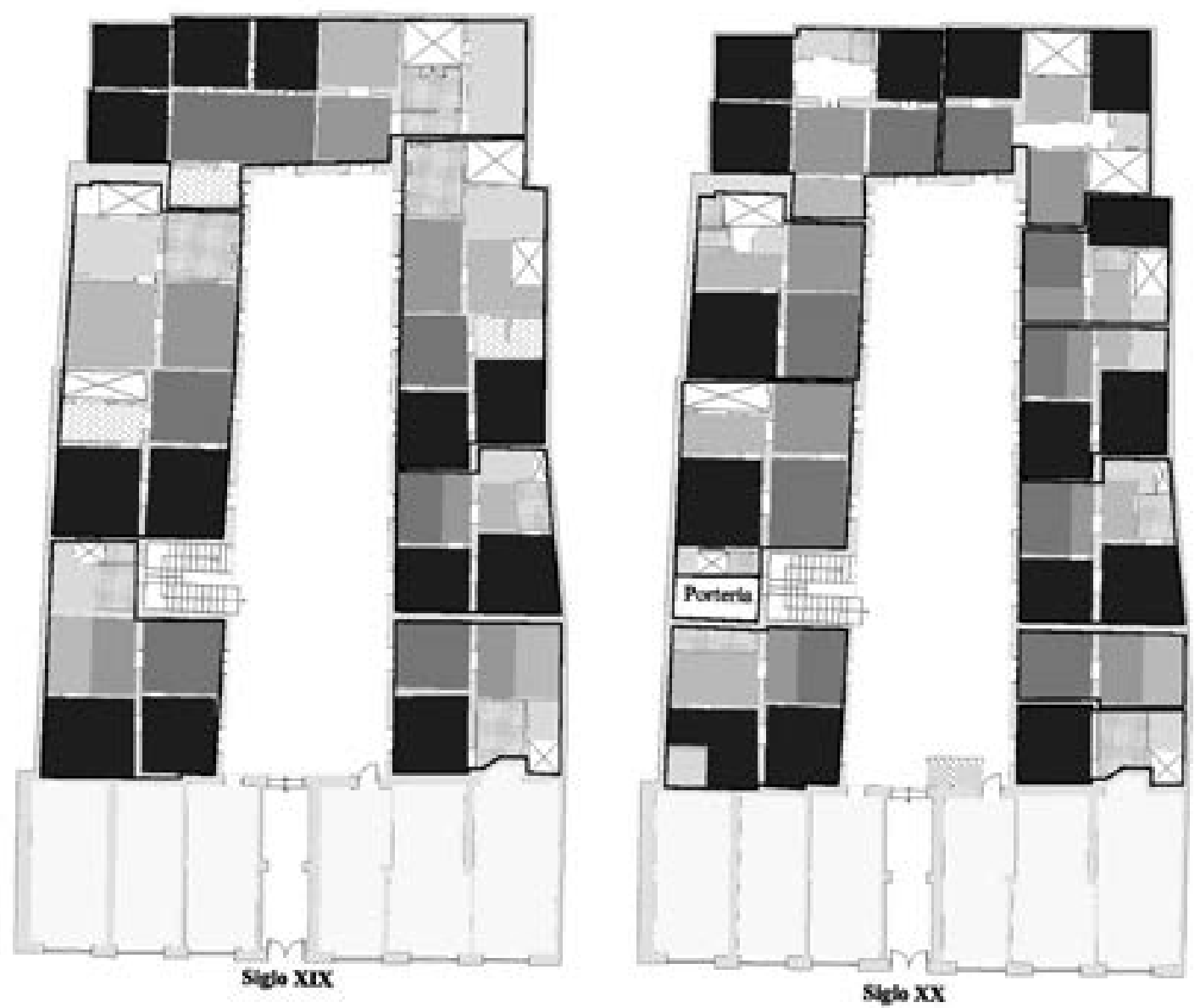

\section{Áreas de actividad.}

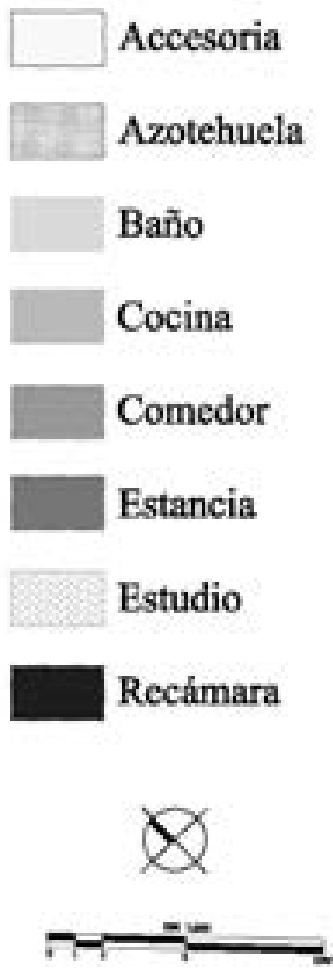

FIGURA 8. Plano de la planta baja de República de Cuba núm. 32, departamentos en el siglo XIX y su subdivisión en el siglo xx (Plano: Patricia Sánchez, 2018; fuente: Sánchez Ramírez 2018: 91).

reutilización del espacio y de la arquitectura previa, entendiendo ese cambio de uso como parte de la continua interacción entre objetos e individuos, de la perpetua relación entre el humano y la transformación de su entorno para aprovechar lo preexistente.

\section{Modificaciones arquitectónicas, cambios culturales}

Las necesidades habitacionales posteriores a la Guerra de Reforma encontraron respuesta en la destrucción del convento de la Concepción y la posterior construcción del edificio de República de Cuba núm. 32 en sus terrenos. Esa primera reapropiación del espacio arquitectónico se determinó a partir del análisis arqueológico arquitectónico del inmueble, así como también fue posible conocer la distribución de espacios al interior de las viviendas y, con ello, plantear hipótesis sobre las diferentes intervenciones que ha sufrido el edificio para adaptarse a las necesidades de cada época.

La primera y más importante adaptación de uso se daría en el siglo XIX, cuando, tras las Leyes de Reforma, se aprovechó un inmueble de la época virreinal para satisfacer las crecientes necesidades de habitación en la ciudad. Fue entonces cuando el edificio adquirió su función actual y, seguramente, su apariencia, con accesorias en planta baja y balcones en la primera y la segunda. Se agregó el segundo nivel y se planearon distribuciones bastante amplias para los departamentos, aunque todas las habitaciones variaban en tamaño, probablemente para dar cabida a diferentes tipos de familias. Asimismo, se incluyeron novedosos materiales, como el acero para los andadores y las marquesinas.

Una segunda intervención se realizó después de la Revolución, que, como en su momento la Guerra de Reforma, trajo consigo un aumento poblacional en la ciudad, y en República de Cuba núm. 32, una subdivisión interna de sus viviendas. Al reducirse los departamentos originales, se crearon más y se generaron habitaciones más compactas, aumentando, así, la capacidad de habitantes en el inmueble (Figura 8). "Las sociedades cambian y consecuentemente sus expectativas de habitabilidad, sus demandas y necesidades concretas, por ello el ejercicio de los arquitectos se ha visto sometido a diversas transformaciones históricas" (Villalobos 2012: 347). 
Los departamentos de República de Cuba núm. 32 evidencian los cambios en el modo de habitar suscitados entre el siglo XVIII y el XIX. En su primera etapa, los espacios hablan de una separación entre los lugares de trabajo y del hogar. En ese sentido, el patio dejó de ser una extensión de la vivienda para recrear trabajos. Se contaba con accesorias específicas para cumplir esa función (Figura 9), característica del modo de vida de finales del siglo XIX. De esa época data el concepto de lo íntimo en el hogar: la familia se vuelve, por excelencia, la representación de lo privado.

Los departamentos construidos en el siglo XIX poseen amplios espacios y una distribución de áreas de actividad. En el tema de la disposición de los espacios, la propuesta de las viviendas propició una vida que le daba prioridad a la vida individual sobre la colectiva. El edificio plurifamiliar heredó de los programas virreinales la presencia de un patio central para las actividades colectivas. Sin embargo, hay una gran diferencia con los programas anteriores, los baños y los lavaderos se integran al interior de cada vivienda, derivado de los ideales decimonónicos sobre higiene y privacidad.

Del mismo modo, se incorporan azotehuelas al interior de las viviendas, lo que introdujo a las mujeres en casa sin que tuvieran ya que exponerse a la vida pública en los lavaderos. Las azotehuelas se distribuyeron generalmente en la entrada, cercanas a la cocina, ya fuesen junto a ésta o aledañas al comedor (Figura 8), lo que señala una relación de género; es decir, se distribuyó como un espacio netamente femenino, ya que en esa época quienes lavaban, cocinaban y servían la comida eran exclusivamente mujeres.

Además, el acceso a los departamentos se limitó por la existencia de un angosto corredor, cuya creación fue posible gracias a los materiales constructivos derivados de la Revolución industrial, como las viguetas y láminas de metal, materiales que aportaron una solución perfecta para ocupar poco espacio, haciendo posible el diseño de estructuras resistentes que permitieran estrechos andadores dentro de los espacios plurifamiliares. Las características de las viviendas de República de Cuba núm. 32 hablan, en su primera etapa, de una clase media pujante, que aspira a un modo de vida más cómodo, a mayor privacidad e intimidad al interior de sus viviendas, dejando a un lado la convivencia de los patios, interiorizando tanto sanitarios como lavaderos y creando los largos y angostos corredores ya referidos, que limitan el espacio de convivencia. "La casa es la expresión material de un sistema de hábitos y un uso específico de la casa en sí y de los objetos que contiene, lo que implica (o debiera implicar) una apropiación previa que determina (o debiera determinar) una elección" (Ortiz 2009: 74).

En el siglo XX, la distribución en los departamentos se modificó drásticamente. En esa segunda etapa, la reducción en su tamaño y en los espacios habitacionales propició que se incorporaran varias actividades a un mismo espacio, esto

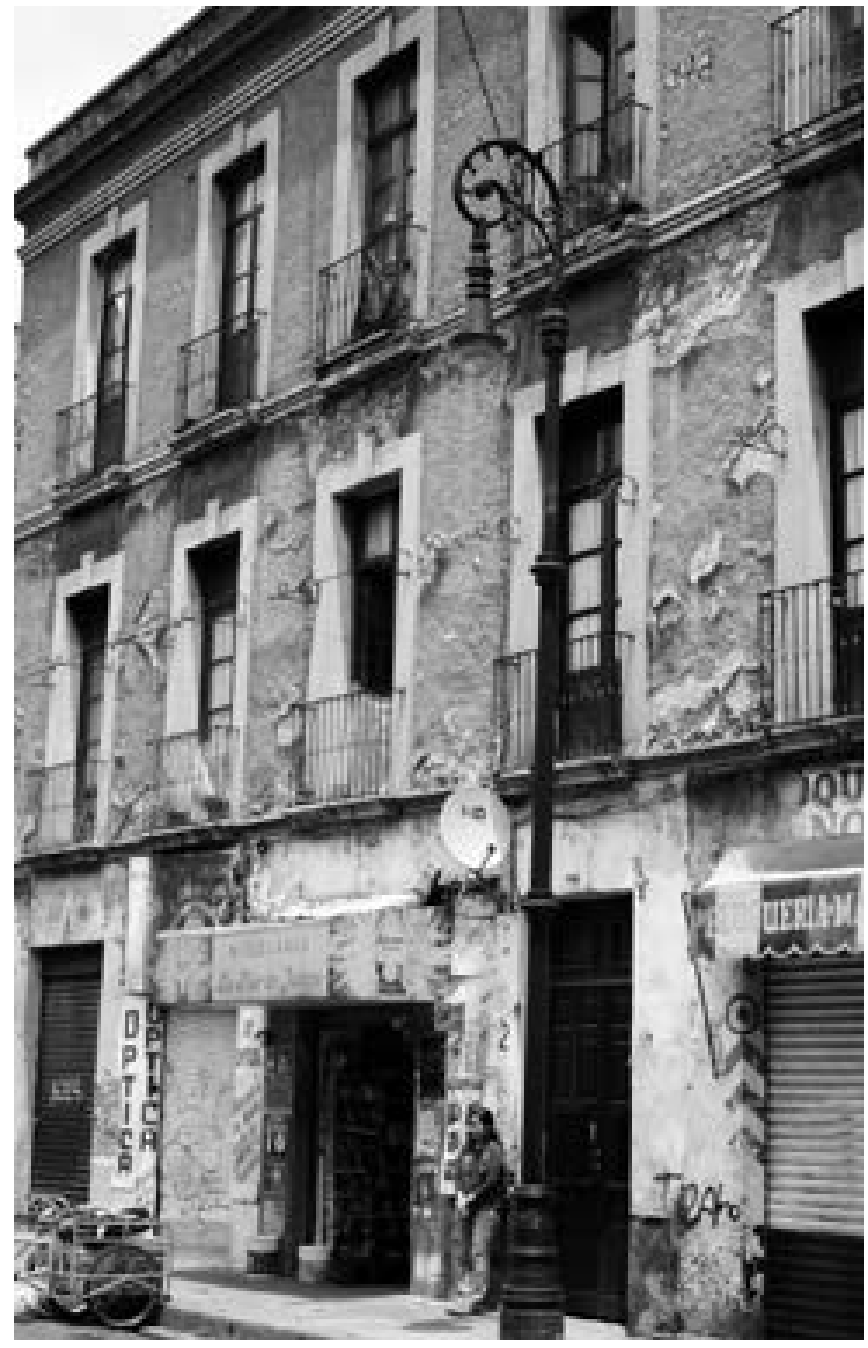

FIGURA 9. Vista de las accesorias en planta baja en fachada de República de Cuba núm. 32 (Fotografía: Patricia Sánchez, 2017).

es, se perdió la separación de actividades por espacio. Por ejemplo, en la mayoría de los casos el área del comedor se fusionó con la sala; en otros, las azotehuelas desaparecieron y se integraron a la cocina (Figura 8).

Se observa, igualmente, la subdivisión de departamentos y la creación de una portería detrás de las escaleras. Asimismo, se construyeron dos baños en el área sur del patio para dar servicio a las accesorias y a la propia portería (Figura 10). Por lo tanto, la entrada a la vida moderna incluyó soslayar la concepción de un espacio por actividad.

La concepción del modo de vida en el siglo xx se transformó, los ideales de habitación del siglo XIX dieron paso a nuevas costumbres y hábitos. En el siglo pasado se determinó reducir el espacio habitable al mínimo posible (y, con ello, las áreas de actividad), para dar cabida a más departamentos en la misma superficie, como consecuencia, también, del constante aumento poblacional suscitado tras el movimiento revolucionario, y, más adelante, del auge migratorio en la década de 1950. La prioridad, entonces, consistió en extender la oferta habitacional al centro de la ciudad. 


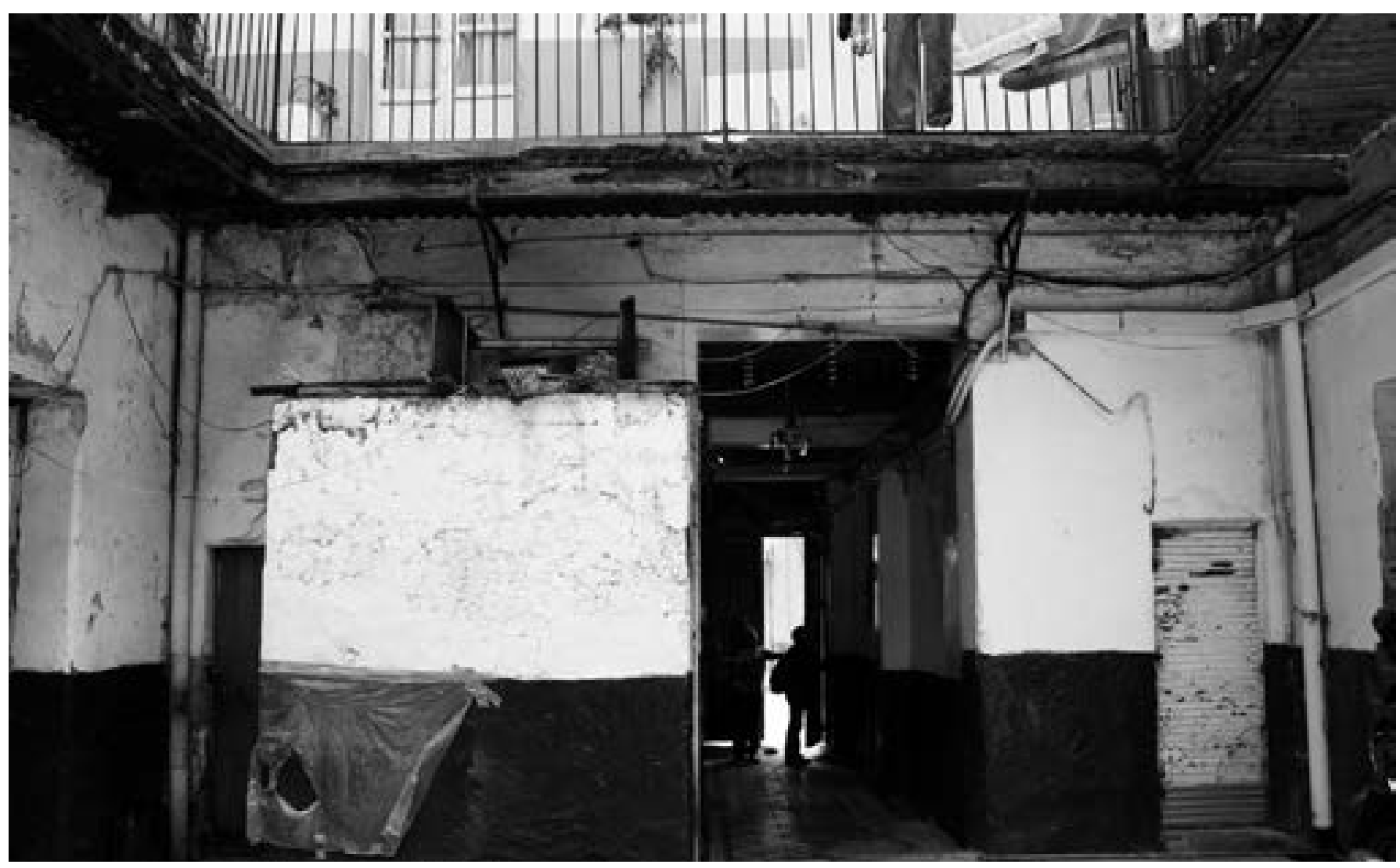

FIGURA 10. Detalle de los baños agregados en el patio central de República de Cuba núm. 32. Vista interior hacia el acceso principal (Fotografía: Patricia Sánchez, 2017).

Una hipótesis para explicar este cambio se encontraría en el entorno. La propia concepción del Centro Histórico de la Ciudad de México se transformó: no se trataba ya de la zona de los grandes palacios donde habitaban sus personajes ilustres. En la Revolución, el centro quedó abandonado en gran medida y fue blanco de saqueos. Después del movimiento social, se consideró como área habitacional, ya no de gente acaudalada, pudiente o de una clase media en ascenso, sino destino de familias de bajos recursos y migrantes. Por esa razón, los departamentos vieron reducidos sus espacios al mínimo, retomando la costumbre de combinar actividades en una misma área, con la necesidad adicional de agregar servicios en el patio, para cubrir la demanda no sólo de la portería y las accesorias sino, quizá, del aumento poblacional en el edificio.

Del mismo modo, el concepto de "vecindad" se modificó. Actualmente el término se usa un tanto indiscriminadamente; si bien aún es aplicable a las arquitecturas sobrevivientes de siglos pretéritos, se ha utilizado también para viviendas modernas (construidas especialmente después del sismo de 1985), las cuales no continuaron con el programa arquitectónico que dio origen a las vecindades del virreinato, pero sí mantuvieron las dinámicas sociales y de convivencia propias de una vecindad. En la actualidad estaríamos hablando de las vecindades como un concepto más social que arquitectónico, que hace referencia a la continuidad de ciertas costumbres de convivencia, especialmente para las clases bajas de la ciudad, donde las características del edifico de República de Cuba núm. 32 coinciden más puntualmente con el antecedente de los departamentos modernos.

\section{Conclusiones}

Las viviendas de la calle República de Cuba núm. 32 son fiel reflejo del contexto que les dio origen. Mediante el análisis arqueológico arquitectónico de sus espacios, se estableció la relación presente entre las transiciones arquitectónicas y las dinámicas sociales en los espacios domésticos. Sus habitantes pertenecían a la clase media emergente del siglo XIX, quienes priorizaron la vida privada al interior de las viviendas, con lo que se establecieron los primeros pasos hacia nuestro modo de vida moderno.

La casa, como unidad social y espacial, posee lo que podría equipararse con una "vida" propia, sincronizada además con los ciclos de vida de sus propios habitantes. Este hecho, resulta fundamental para poder comprender un inmueble así como las huellas (registro arqueológico) de los eventos que ocurrieron y que marcaron cambios significativos en función de los diferentes tipos de espacio; de ahí 
la importancia de analizar las partes que componen esa unidad denominada casa [Cohen 2011: 9].

En relación con el análisis de materiales y sistemas constructivos, la arqueología de la arquitectura permite argumentar que se trata de un conjunto de viviendas que sentaría las bases para los futuros edificios departamentales. Es decir, el uso de buenos materiales, como el ladrillo - no bloques de adobe como en otros casos-y, primordialmente, el sistema de lámina acanalada y vigueta metálica para los andadores y pasillos internos, además de marquesinas de metal, son indicadores de un grupo social con cierto poder adquisitivo, que se permitió el "lujo" de habitar un inmueble con las tecnologías constructivas más novedosas. Al analizar los espacios y sistemas constructivos mediante la aplicación de la arqueología de la arquitectura, es posible conocer y entender las técnicas y tradiciones constructivas que se han descontinuado con el tiempo y que caracterizan periodos específicos en la historia de la arquitectura. Metodologías que es necesario recuperar - y no olvidar - para integrar al conocimiento de la conservación y, por ende, a los proyectos de restauración arquitectónica. Si bien el aporte de la disciplina va más allá, por medio de ésta es posible detectar los añadidos y falsificaciones efectuados en los procesos de restauración de los propios edificios, donde no siempre se advierten a simple vista.

$\mathrm{Y}$ aunque cada vez son más los proyectos interdisciplinarios en nuestro país, los que llegan a incluir metodologías provenientes de la arqueología de la arquitectura no siempre los reconocen como tales. Hace falta homogenizar conceptos e identificar a la disciplina con un término concreto, cuya definición se estableció desde finales del siglo pasado. Todo lo cual indica que aún hay trabajo por hacer en este campo.

Las distintas disciplinas encargadas e interesadas en la conservación de los monumentos, en especial la arqueología y la arquitectura, deben plantearse desde perspectivas comprometidas totalmente con el conocimiento y la gestión del patrimonio construido y, a la vez, reconocerse obligadas a responderle a la sociedad. Para alcanzar la meta, quizá lo primero sería romper el paradigma: "Ni los arquitectos restauradores consideran prioritaria la aportación de la arqueología para la definición de sus intervenciones, ni los arqueólogos consiguen verse a sí mismos más allá de unos simples excavadores" (Azkarate et al. 2002: 9).

Son conocidos los contrastes entre arqueólogos y arquitectos dentro de los trabajos en monumentos históricos. En oposición a considerarse aliados, ambas disciplinas suelen encontrar mutua incomprensión, limitando con ello el diálogo cooperativo. Se requiere ir más allá de un análisis arquitectónico, e incluir la interdisciplina como parte necesaria en cualquier estudio de conservación patrimonial, en especial en el campo de los monumentos, leyéndolos como documentos arquitectónicos.
Por otro lado, no está de más recalcar la importancia y el valor histórico del edificio de República de Cuba núm. 32 como testimonio de arquitectura transicional, al usar materiales tradicionales e innovadores así como al aplicar un programa de arquitectura doméstica que buscaba priorizar la privacidad de sus habitantes por encima de la vida colectiva. Sin embargo, también representa un valioso ejemplo de cómo la vivienda puede ser un detonador de conservación del patrimonio, en particular en zonas patrimoniales como los centros históricos (Suárez 2009); aspecto relevante al ser un inmueble catalogado por el Instituto Nacional de Antropología e Historia (clave catálogo 090150070389) que ha mantenido su función habitacional desde su construcción.

El otorgarle un valor de uso a los inmuebles históricos, más allá de convertirlos en oficinas, hoteles, museos o centros culturales, se da cuando se satisface una necesidad social, en este caso, la habitacional. "Un sentido de aprecio hacia determinados objetos por el mérito que atesoran, por la utilidad que manifiestan, o por su aptitud para satisfacer necesidades o proporcionar bienestar" (Ballart 1997: 61).

\section{Referencias}

Ayala Alonso, Enrique

2009 La idea de habitar: la Ciudad de México y sus casas, 1750-1900. México, Universidad Autónoma MetropolitanaXochimilco.

Azkarate Garai-Olaun, Agustín, Luis Caballero Zoreda y Juan Antonio Quirós Castillo

2002 "Arqueología de la arquitectura: definición disciplinar y nuevas perspectivas", Arqueología de la Arquitectura 1: 7-10.

Ballart, Josep

1997 El patrimonio histórico y arqueológico: valor y uso, Barcelona, Ariel.

Cohen Daza, David

2011 "Arqueología de la arquitectura. Una aproximación al estudio de los edificios", tesis de magíster en patrimonio cultural y territorio, Bogotá, Facultad de Arquitectura y Diseño Pontificia Universidad Javeriana.

Herrera Moreno, Ethel, y Concepción de Ita Martínez

1992500 planos de la Ciudad de México: 1325-1933, México, SAHOP.

Katzman, Israel

1993 Arquitectura del siglo XIX en México, México, Trillas.

Mannoni, Tiziano

1990 "Archeologia dell'architettura", Notiziario di Archeologia Medievale 54: 28-29.

Martín Hernández, Vicente

1981 Arquitectura doméstica de la Ciudad de México, 18901925. México, Universidad Nacional Autónoma de México.

Morales, María Dolores, y María Gayón

2001 "Viviendas, casas y usos de suelo en la Ciudad de México. 1848-1882", en Rosalva Loreto López (comp.), Casas, 
viviendas y hogares en la historia de México, México, El Colegio de México, pp. 339-376.

Muriel, Josefina

1992 "La habitación plurifamiliar en la Ciudad de México", en La ciudad y el campo en la historia de México, Memoria de la VII Reunión de Historiadores Mexicanos y Norteamericanos, 23-26 de octubre de 1985, t. I, México, Universidad Nacional Autónoma de México, pp. 267-282.

Ortiz Marín, Víctor Manuel 2009 La casa, una aproximación, México, Universidad Autónoma Metropolitana-Xochimilco.

Pérez Bertruy, Ramona Isabel 2012 Imágenes de la Alameda de la Ciudad de México. Tres siglos de historias y proyectos, México, Gobierno del Distrito Federal-Secretaría de Cultura.

Quirós Castillo, Juan Antonio 1994 "Contribución al estudio de la arqueología de la arquitectura", Arqueología y Territorio Medieval 1: 141-158.

Sánchez Ramírez, Patricia Viridiana

2018 “La arquitectura doméstica de República de Cuba \# 32, Centro Histórico. Arqueología de la arquitectura", tesis de maestría en arquitectura, restauración del patrimonio arquitectónico, México, Universidad Nacional Autónoma de México.

Serrano Pozuelo, Rosa María

2013 "Arqueología de la arquitectura. Nacimiento y desarroIlo en España", Arqueoweb 14, 2012-2013: 119-148.

Suárez Pareyón, Alejandro 2009 "La función habitacional del centro histórico y el desafío de su regeneración", en Seminario Permanente Centro Histórico de la Ciudad de México, vol. 1. México, Universidad Nacional Autónoma de México-Programa Universitario de Estudios sobre la Ciudad, pp. 35-52.
Villagrán García, José 1989 Teoría de la arquitectura, México, Universidad Nacional Autónoma de México.

Villalobos Pérez, Alejandro 1992 "Urbanismo y arquitectura mesoamericana: una perspectiva", tesis doctoral en arquitectura, México, Universidad Nacional Autónoma de México.

2012 "Elementos para una arqueología de la arquitectura en el México antiguo", en Iván San Martín Córdova y Mónica Cejudo Collera (comp.), Teoría e historia de la arquitectura. Pensar, hacer y conservar la arquitectura, México, Universidad Nacional Autónoma de México, pp. 347-354.

\section{Síntesis curricular del/los autor/es}

\section{Patricia Viridiana Sánchez Ramírez}

Universidad Nacional Autónoma de México (UNAM), México yax_kinn@hotmail.com

Arqueóloga (Escuela Nacional de Antropología e Historia [ENAH-INAH], México), y maestra en arquitectura en el área de restauración del patrimonio arquitectónico (Universidad Nacional Autónoma de México [UNAM], México). Trabajó en diversos proyectos de investigación del Programa Universitario de Estudios de la Diversidad Cultural y la Interculturalidad de la UNAM. Desde el año 2010, ha colaborado en proyectos de salvamento arqueológico en los estados de Hidalgo, Oaxaca, Puebla, Chiapas, Yucatán y, principalmente, en la Ciudad de México. El interés de sus trabajos se ha enfocado en la arquitectura prehispánica e histórica, la relación entre cultura material y dinámicas sociales, el patrimonio cultural y su conservación y difusión. 